\title{
PROJETOS DE APRENDIZAGEM GAMIFICADOS: Uma metodologia inventiva para a educação na cultura híbrida e multimodal
}

\author{
GAMIFICATION LEARNING PROJECTS: \\ An inventive methodology for the education in the hybrid and multimodal \\ culture
}

Profa. Dra. Eliane Schlemmer ${ }^{1}$

\begin{abstract}
Resumo: $O$ artigo resulta de pesquisas desenvolvidas pelo Grupo de Pesquisa Educação Digital - GPe-dU UNISINOS/CNPq e busca responder à seguinte questão de pesquisa: como a gamificação, aliada a elementos do método cartográfico de pesquisa-intervenção e, dos projetos de aprendizagem pode contribuir para o desenvolvimento de metodologias inventivas, considerando a educação na cultura híbrida e multimodal? O objetivo foi compreender o potencial da gamificação, do método cartográfico de pesquisa-intervenção e dos projetos de aprendizagem para 0 desenvolvimento de metodologias inventivas. A pesquisa é qualitativa, exploratória e descritiva e fez uso do método cartográfico de pesquisaintervenção. Utilizou observação participante, diário de bordo e registros em diferentes formatos. Entre os principais resultados estão: a criação de situações de aprendizagem; aprofundamento conceitual e; o desenho da Metodologia de Projetos de Aprendizagem Gamificados.
\end{abstract}

Palavras-chave: educação, metodologia inventiva, hibridismo e multimodalidade.

\begin{abstract}
The paper results from researches developed by the Digital Education Research Group - UNISINOS/CNPq and investigates how the gamification, allied to elements of the research-intervention cartographic method and the learning projects can contribute for the development of the inventive methodologies, considering education in the hybrid and multimodal culture. The study goal was to understand the potential of the gamification, of the research-intervention cartographic method and of the learning projects for the inventive technologies development. The research is

\footnotetext{
${ }^{1}$ Bolsista Produtividade em Pesquisa do CNPq, Professora Pesquisadora Titular do Programa de Pósgraduação em Educação da UNISINOS
} 
qualitative, exploratory and descriptive and uses the intervention-research cartographic method. As instruments and materials were used participant observation, logbook, and records in different formats. As research results, we have the creation of learning situations, the conceptual deepening and the Gamified Learning Projects methodology design.

Keywords: gamification, cartography, learning projects, hybridism and multimodality

Keywords: education, inventive methodology, hybridism and multimodality.

\section{Introdução}

O sistema educacional é constituído por diferentes culturas, entre elas a cultura da instituição escola/universidade, a cultura da formação de professores e, ainda as culturas dos diferentes sujeitos que a integram. Esse sistema escola/universidade está imbricado num determinado sistema de sociedade, mas de que sociedade estamos falando? Como o sistema escola/universidade conversa com o sistema sociedade? É nesse sistema escola/universidade, que trabalha com desenvolvimento humano, que temos a possibilidade, tanto reproduzir essa sociedade como trabalhar no sentido da mudança e isso está em grande parte, relacionado com o ethos desse sistema.

Esse mesmo sistema escola/universidade está inserido numa política educacional e, reproduz e/ou desenvolve estruturas e formas de funcionamento, com suas organizações curriculares, metodologias e práticas pedagógicas, representado concepções e valores sócioculturais.

Esses valores sócio-culturais estão sendo alterados significativamente no contexto de uma sociedade em rede (CASTELLS, 1999), interligada, conectada, permeada pela presença contínua e constante de tecnologias de toda a natureza. No entanto, no âmbito do sistema escola/universidade, ainda se percebe uma dificuldade em realizar mudanças que sejam significativas para os atuais sujeitos da aprendizagem e que possam ser percebidas pela sociedade. Todo esse movimento, nos instiga a pensar numa epistemologia reticular, conectiva e atópica (DI FELICE, 2009, 2012), e tem inspirado algumas construções técnico-teóricasmetodológicas, desenvolvidas nas pesquisas realizadas pelo Grupo de Pesquisa Educação Digital - GPe-dU UNISINOS/CNPq, vinculado a Linha de Pesquisa Educação, 
Desenvolvimento e Tecnologias do Programa de Pós-Graduação em Educação da Universidade do Vale do Rio dos Sinos - UNISINOS.

\section{Contexto}

O presente artigo se contextualiza nos resultados evidenciados em Schlemmer (2013, 2016, 2017) os quais possibilitam propor o desenho da metodologia de "Projetos de Aprendizagem Gamificados", o qual tem origem na metodologia de Projetos de Aprendizagem, proposta por Fagundes, Maçada e Sato (1999); na metodologia de Projetos de Aprendizagem baseado em Problemas, adaptada para o ensino superior por Schlemmer (2001, 2002), Trein e Schlemmer (2009); no método cartográfico de pesquisa-intervenção, adaptado enquanto prática pedagógica por Schlemmer \& Lopes (2012, 2016), Schlemmer (2014), Schlemmer, Chagas, Schuster (2015) e, no conceito e elementos de gamificação propostos por Schlemmer (2014, 2015, 2016).

A metodologia "Projetos de Aprendizagem Gamificados" tem sido desenvolvida com doutorandos, mestrandos, graduandos, professores e estudantes da Educação Básica, em municípios do estado do Rio Grande do Sul, na perspectiva da ampliação dos espaços de aprendizagem para a Cidade constituindo, dessa forma, espaços de convivência (MATURANA, 2002) híbridos, multimodais, pervasivos e ubíquos (SCHLEMMER 2015, 2016), a partir de uma proposta que inclui o desenvolvimento de games \& processos gamificados, considerando a abordagem proposta pelo movimento "Games for Change". Nesse processo, por meio dos movimentos da cartografia, os sujeitos da aprendizagem realizam a leitura de seu cotidiano, o que inclui os espaços geográficos nos quais se movimentam, e buscam identificar problemáticas sociais relevantes para as quais podem contribuir, a partir do desenvolvimento de um game ou processo gamificado. Fazem uso dos espaços públicos e pessoas da comunidade, enquanto pistas geográficas e pistas vivas, respectivamente, que podem contribuir com informações no contexto do desenvolvimento de uma determinada missão no game ou processo gamificado. Assim, criam-se as bibliotecas vivas da cidade. Essa metodologia tem resultado em práticas de impacto social relevante, contribuindo significativamente para o desenvolvimento da cidadania.

A relevância da temática, bem como o seu caráter inovador está relacionado a necessidade de desenvolver metodologias inventivas e práticas pedagógicas agregativas, a partir de uma concepção epistemológica reticular, conectiva e atópica, apoiadas nas mais recentes teorias, 
entre elas a cognição enativa, a cognição inventiva e a Teoria Ator-Rede. Dessa forma, buscase propor metodologias e práticas que sejam significativas para os atuais sujeitos da aprendizagem e objetivem um processo de desenvolvimento emancipatório e cidadão. É nesse contexto que tem origem o problema e objetivos da pesquisa, apresentados a seguir.

\section{Problema e Objetivos da Pesquisa}

O problema de pesquisa que dá origem a esse artigo pode ser assim expresso: Como a gamificação, aliada a elementos presentes no método cartográfico de pesquisa-intervenção e nos projetos de aprendizagem pode contribuir para o desenvolvimento de metodologias inventivas, considerando a educação na cultura híbrida e multimodal?

O objetivo principal consistiu em compreender o potencial da gamificação, do método cartográfico de pesquisa-intervenção e dos projetos de aprendizagem para o desenvolvimento de uma metodologia mais significativa aos atuais sujeitos da aprendizagem, que integram a cultura híbrida e multimodal. A seguir são apresentados os pressupostos teóricos que fundamentam o desenvolvimento de metodologia inventiva Projetos de Aprendizagem Gamificados

\section{Pressupostos teóricos}

As metodologias que atualmente desenvolvemos, bem como as práticas pedagógicas são herdeiras de uma determinada compreensão epistemológica e se fundamentam em teorias de aprendizagem construídas numa cultura pré-digital, deixando, portanto, de contemplar questões próprias de uma cultura digital ou ainda de uma cultura híbrida e multimodal, bem com as novas compreensões teórico-epistemológicas que se constituem a partir das novas subjetividades que estão sendo construídas.

Nessa perspectiva vimos a Escola Nova de James, Dewey e Chalaparède, que propõe a metodologia de ensino centrada na aprendizagem pela experiência e o desenvolvimento da autonomia do sujeito, dar origem as metodologias ativas. O que fundamenta essa perspectiva metodológica é a epistemologia interacionista, que compreende que o conhecimento não está nem sujeito e nem no objeto, mas sim na interação entre eles, sendo o sujeito ativo nesse processo. 
Essa tradição epistemológica é antropocêntrica (LATOUR 1994, 2012); a interação supõe a pré-existência dos dois termos (organismo e meio) que interagem e; o conhecimento é compreendido como representação, não mais de um mundo externo ao sujeito, como acreditavam os empiristas, cognitivistas e conexionistas, mas como representação interna ao sujeito, portanto, significação (KASTRUP, TEDESCO e PASSOS, 2015).

Entre os principais autores dessa tradição estão: Piaget, Vygotsky, Rogers, Bruner, Ausubel, Freire, sendo que cada um deles construiu uma teoria robusta que possui especificidades, as quais precisam ser conhecidas e apropriadas para que possamos, a partir da análise do mundo contemporâneo, estabelecer relações com as novas construções epistemológicas e teóricas que estão surgindo, a fim de avançarmos na compreensão e produção do conhecimento.

\section{A Pedagogia por Projetos}

A pedagogia por projetos tem origem nos EUA, mais especificamente com os trabalhos desenvolvidos pelo pedagogo William Heard Kilpatrick, inspirado pelo filósofo e psicólogo também americano, John Dewey, e pelo movimento da Escola Nova, originário da Europa. Esses trabalhos foram sistematizados no livro The Project Method, em 1918, trazendo a perspectiva de que a escola precisava ser mais democrática e centrada no estudante. Com a metodologia de projetos, Kilpatrick apresenta uma alternativa ao ensino tradicional, baseado num currículo estruturado por disciplinas e centrado num conteúdo a ser ensinado, por meio de rotinas pré-definidas e na memorização, cujo professor é o detentor do conhecimento. Ele defende um currículo centrado na vida, nos problemas que tem origem no cotidiano, nas experiências dos sujeitos da aprendizagem. Nesse contexto a prática do professor se modifica e ela passa a ser um orientador do processo de aprendizagem dos estudantes. No Brasil inspirou o movimento da Escola Nova, liderado por Anísio Teixeira, em 1930.

Desde então, a metodologia de projetos vem se desenvolvendo, se transformando, conforme os significados que são construídos, o que dá origem a diferentes concepções sobre projetos, tais como: projetos de ensino, projetos de trabalho, projetos de aprendizagem, entre outros. Entretanto, o que une essas distintas abordagens é a concepção epistemológica interacionista e a proposta de que o processo de ensino e de aprendizagem se desenvolva a partir da solução de problemas. 
Em meio a distintas denominações, encontramos ainda uma confusão da metodologia de projetos com a proposta de centros de interesse, plano de unidade, trabalho por temas, pesquisa do meio, dentre outras, as quais apresentam diferenciações significativas entre si.

A metodologia de Projetos de Aprendizagem, tem origem nos resultados de pesquisas em "psicologia genética, sobre o desenvolvimento da inteligência e sobre o processo de aprendizagem", realizadas pelo Laboratório de Estudos Cognitivos - LEC/UFRGS. Essa metodologia foi amplamente investigada pelo LEC/UFRGS, no contexto do Projeto Amora ${ }^{2}$, desenvolvido no Colégio da Aplicação da UFRGS, e também em outros colégios da Rede Municipal de Educação de Porto Alegre-RS, o que deu origem a Obra "Aprendizes do futuro: as inovações começaram!”, de Fagundes, Maçada e Sato (1999). Essa metodologia foi adaptada para o ensino superior, passando a se denominar Metodologia de Projetos de Aprendizagem Baseada em Problemas. (SCHLEMMER 2001, 2002).

Fundamentadas na concepção epistemológica interacionista-construtivista, as autoras referem a importância da formulação de questões pelo autor do projeto, ou seja, o sujeito que irá construir o conhecimento, a partir do que já conhece e da curiosidade, inquietações, conflitos, perturbações num determinado contexto, em seu ambiente de vida. É a partir dessas questões, sobre as quais deseja conhecer, que o aprendiz vai se movimentando, interagindo "com o desconhecido, ou com novas situações, a fim de se apropriar de conhecimento específico - seja nas ciências, nas artes, na cultura tradicional ou na cultura em transformação". (FAGUNDES, SATO E MAÇADA, 1999, p. 17). As autoras salientam que a questão a ser pesquisada, precisa surgir do aprendiz e não seja imposta pelos professores, pois, a motivação é intrínseca, própria do sujeito que aprende.

\footnotetext{
"Essa inversão de papéis pode ser muito significativa. Quando o aprendiz é desafiado a questionar, quando ele se perturba e necessita pensar para expressar suas dúvidas, quando lhe é permitido formular questões que tenham significação para ele, emergindo de sua história de vida, de seus interesses, seus valores e condições pessoais, passa a desenvolver a competência para formular e equacionar problemas. Quem consegue formular com clareza um problema, a ser resolvido, começa a aprender a definir as direções de sua atividade." (FAGUNDES, SATO E MAÇADA, 1999 p. 16).
}

Desenvolver projetos é uma atividade que requer trabalhar om o outro (colaboração) e também realizar operações mentais com o outro (cooperação). Dessa forma a metodologia

\footnotetext{
${ }^{2}$ http://www.ufrgs.br/projetoamora/
} 
incentiva a aprendizagem da colaboração e da cooperação, a partir da necessidade de trocas recíprocas e respeito mútuo.

\begin{abstract}
"Isto quer dizer que a prioridade não é o conteúdo em si, formal e descontextualizado. A proposta é aprender conteúdos, por meio de procedimentos que desenvolvam a própria capacidade de continuar aprendendo, num processo construtivo e simultâneo de questionar-se, encontrar certezas e reconstruí-las em novas certezas. Isto quer dizer: formular problemas, encontrar soluções que suportem a formulação de novos e mais complexos problemas. Ao mesmo tempo, este processo compreende o desenvolvimento continuado de novas competências em níveis mais avançados, seja do quadro conceitual do sujeito, de seus sistemas lógicos, seja de seus sistemas de valores e de suas condições de tomada de consciência." (FAGUNDES, SATO E MAÇADA, 1999 p. 24).
\end{abstract}

No processo de aprender, buscar a informação não basta, ela é somente um dos elementos, sobre o qual os aprendizes precisam estabelecer relações a fim de gerar conhecimento. Assim, segunda as autoras, não há interesse em registrar se o aprendiz retém ou não uma informação, aplicando um teste ou uma "prova" objetiva, pois, isso não nos dá elementos para compreender se ele construiu um conhecimento novo.

\begin{abstract}
"O que interessa são as operações que o aprendiz possa realizar com estas informações, as coordenações, as inferências possíveis, os argumentos, as demonstrações. Pois, para construir conhecimento, é preciso reestruturar as significações anteriores, produzindo boas diferenciações e integrando ao sistema as novas significações. Esta integração é resultado da atividade de diferentes sistemas lógicos do sujeito, que interagem entre si e com os objetos a assimilar ou com os problemas a resolver. Finalmente, o conhecimento novo é produto de atividade intencional, interatividade cognitiva, interação entre os parceiros pensantes, trocas afetivas, investimento de interesse e valores... O importante é observar não $o$ resultado, um desempenho isolado, mas como o aluno está pensando, que recursos já pode usar, que relações consegue estabelecer, que operações realiza ou inventa." (FAGUNDES, SATO E MAÇADA, 1999 p. 24).
\end{abstract}

No contexto de Projetos de Aprendizagem, os professores, além de serem especialistas, são também aprendizes e passam a ser ativadores da aprendizagem, articuladores da prática, orientadores dos projetos.

A Metodologia de Projetos de Aprendizagem Baseada em Problemas, adaptada ao ensino superior, segundo Schlemmer (2002) foi desenvolvida, tendo como fundamento a epistemológica interacionista-construtivista-sistêmica, os estudos de Maturana e Varela, Castells, Levy, Fagundes, Sato e Maçada, Hernandez e Ventura, a fim de subsidiar práticas pedagógicas inovadoras que favorecessem a constituição de comunidades virtuais de aprendizagem no paradigma da Sociedade em Rede. 
A proposta, segundo a autora, é baseada no pressuposto da atividade cooperativa, envolve diversos espaços de interação (presenciais físicos e digitais, sendo alguns online) e possibilita um processo de ação-reflexão continuados dos sujeitos da aprendizagem. O pressuposto da atividade cooperativa inclui e incentiva a possibilidade de um trabalho interdisciplinar, pois, oportuniza o desenvolvimento do pensamento e da autonomia por meio de trocas intelectuais, sociais, culturais e políticas, favorecendo a tomada de consciência (PIAGET, 1978).

\footnotetext{
"A metodologia implica num projeto comunicacional descentrado, porém mediado, em praticamente todas as funções interativas possíveis nos diferentes espaços. Desta forma procura disponibilizar meios efetivos para uma multiplicidade de significações que se originam nos esquemas dos sujeitos. Os professores passam a ter a função de orientadores, articuladores, problematizadores, pesquisadores e especialistas na comunidade de aprendizagem. Isto implica em participar, instigar a discussão, acompanhar e analisar a construção do conhecimento por meio da participação individualizada nos espaços de interação disponibilizados no ambiente." (SCHLEMMER, 2002, p. 189).
}

A avaliação é usada para verificar como o sujeito está pensando, que recursos já utiliza, que relações consegue estabelecer, que operações realiza ou inventa, ou seja, há um acompanhamento de todo o desenvolvimento da aprendizagem.

Dessa forma, é fundamental a mediação pedagógica do professor e a possibilidade de interação entre os atores envolvidos. São essas premissas que fazem a diferença na qualidade de um processo educacional, no qual se prioriza a aprendizagem e a cooperação. Durante a aprendizagem, é necessário um processo de reflexão do próprio sujeito sobre sua ação. O que muitas vezes ocorre é a imposição de uma única lógica responsável por transmitir o conhecimento, ao invés de propiciar o desenvolvimento lógico de cada um, o qual possibilitaria ao sujeito reconstruir conceitos, estabelecer relações, entender seu próprio processo de aprendizagem, melhorando sua auto-estima. Essa preocupação é expressa por Papert (1996), para quem "a melhor aprendizagem ocorre quando o aprendiz assume o comando". (p.29). Essa proposta pode ser viabilizada através do uso de diferentes tecnologias digitais que permitam a constituição de comunidades virtuais. Essas comunidades podem ser formadas por professores e estudantes, caracterizando-se num espaço para partilhar recursos materiais e informacionais, que ambos possuem. Os professores também aprendem ao mesmo tempo que os estudantes, atualizam continuamente tanto seus saberes "disciplinares", ou seja, na disciplina em que são especialistas, quanto desenvolvem e transformam suas práticas pedagógicas. Dessa forma, a compreensão de um processo de trabalho que propicie a interdisciplinaridade precisa levar em 
conta uma mudança profunda na forma como o professor é formado. Precisa priorizar a possibilidade de troca e reciprocidade, considerar o próprio processo de formação do professor, suas concepções de aprender e ensinar, numa constante redefinição da própria práxis em contato com seus pares. "A principal função do professor não pode mais ser uma difusão dos conhecimentos, que agora é feita de forma mais eficaz por outros meios. Sua competência deve deslocar-se no sentido de incentivar a aprendizagem e o pensamento". (LÉVY, 1999 p. 171). O professor assume o papel de animador da inteligência coletiva dos grupos com os quais está interagindo, centrando sua atividade no acompanhamento e na gestão das aprendizagens: problematizando, desafiando, incitando a curiosidade, a troca de informações, proporcionando a autonomia no processo da aquisição de novos saberes, desenvolvendo a cooperação, a mediação relacional e simbólica, dentro outras. Portanto, o que vai determinar a forma como os diferentes tecnológicas serão utilizadas, são os pressupostos epistemológicos presentes na prática do docente.

Assim, os projetos de aprendizagem baseados em problemas podem ser desenvolvidos a partir de plataformas livres ou temáticas (definidas em conjunto com os professores) onde os aprendizes, num processo de discussão, relacionam suas certezas provisórias e dúvidas temporárias. A partir desse momento, os grupos são formados tendo como base as dúvidas em comum. Criados os grupos inicia-se o planejamento do projeto, no qual os aprendizes relacionam o que sabem sobre a problemática que desejam investigar e o que ainda não sabem e, portanto precisam pesquisar. Descrevem os objetivos do projeto, como vão desenvolvê-lo, como vão produzir as informações, que recursos e materiais vão utilizar, bem como a forma como será socializado. Essa organização varia de grupo para grupo, não existe uma ordem ou regra pré-definida para a estruturação do projeto de aprendizagem baseado em problema. $\mathrm{O}$ projeto começa a ser construído e o trabalho se desenvolve durante todo o percurso da formação, de forma colaborativa e cooperativa entre todos. Na medida em que vai sendo construído fica disponibilizado para que os demais, possam fazer seus comentários e dar suas contribuições. Além disso, durante o processo existem momentos específicos para a socialização dos projetos, o primeiro quando é concluída a fase de planejamento e pesquisa e, o segundo, quando concluem o projeto. Nesses momentos, um grupo avalia o outro a partir de alguns critérios definidos em conjunto. As diferentes tecnologias potencializam a metodologia de projetos de aprendizagem baseados em problema, pois é por meio delas que ocorre a organização dos 
participantes, a partir de interesses mútuos que dão origem aos grupos de trabalho para desenvolver os projetos. Os integrantes dos grupos, utilizando as ferramentas do Google, comunicadores instantâneos, mídias sociais, entre outros, realizam pesquisas e entrevistas, se comunicam, a fim de buscar elementos e estabelecer processos de reflexão e discussão capazes de levar a uma maior compreensão da temática investigada, responder as dúvidas temporárias e confirmar ou não as certezas provisórias com relação ao problema investigado. Por meio da significação de diferentes tecnologias os projetos de aprendizagem baseados em problemas vão se constituindo, vão sendo desenhados, adquirindo contornos, e sendo socializados no percurso, evidenciando o processo em construção. Os cadernos, blogs, funpages, etc, possibilitam ao professor e a todos os participantes ter acesso a todo o processo que está sendo desenvolvido, criando uma rede de trabalho, de colaboração e de cooperação efetiva em torno das diferentes problemáticas investigadas.

Vinculado a metodologia de projetos de aprendizagem baseados em problema, está a elaboração dos diários do percurso onde os aprendizes registram suas aprendizagens, percepções, dúvidas, dificuldades e sentimentos em relação a elas. O diário se constitui num importante espaço para tomada de consciência e para a metacognição dos, pois possibilita aos aprendizes analisar, refletir sobre o seu processo da aprendizagem, favorecendo o pensar sobre o pensar. Para o professor, o diário fornece indicadores sobre o processo de desenvolvimento dos aprendizes, possibilitando um acompanhamento individualizado, o que lhe permite interagir com cada um, individualmente, fornecendo feedback, problematizando, instigando de forma a provocar novas reflexões e aprendizagens. Essa prática fornece subsídios para que o professor possa regular o processo de ensino, de forma que melhor atenda as necessidades individuais e coletivas dos sujeitos da aprendizagem.

\section{O método cartográfico de pesquisa-intervenção}

O método cartográfico de pesquisa-intervenção, tem sua origem no método cartográfico, proposto por Deleuze e Guattari (1995) e tem sido explicitado e investigado no Brasil por Kastrup (2007; 2008), Passos, Kastrup e Escóssia (2009) e Passos, Kastrup e Tedesco (2014), enquanto método de pesquisa.

Os autores afirmam que a cartografia é um método que objetiva acompanhar processo por meio de pistas que orientam o percurso da pesquisa, considerando os efeitos do processo do “pesquisar" sobre objeto da pesquisa, o pesquisador e seus resultados, e não simplesmente 
representar um objeto, o que a diferencia de outras abordagens cujo foco está no resultado final e não no processo desenvolvido.

Trata, portanto, de investigar um processo de produção, sem estabelecer um caminho linear para atingir um fim. O cartógrafo, pessoa que desenvolve a cartografia, o faz por meio da "atenção cartográfica". A atenção cartográfica, de acordo com Kastrup (2007, p.15), está baseada no conceito de "atenção flutuante" de Freud e no conceito de "reconhecimento atento" de Bergson. Assim, define a atenção cartográfica como concentrada e aberta, caracterizandose por quatro variedades (movimentos): o rastreio, o toque, o pouso e o reconhecimento atento.

O trabalho do cartógrafo tem início pelo rastreio - varredura no campo, compreendido como um voo, cuja a atenção é aberta e sem foco. Não se refere simplesmente a busca de informação, mas a um olhar amplo, até que algo toque. O toque - representa a primeira significação, ou seja, a primeira análise feita sobre o processo de seleção. É caracterizado por uma rápida sensação de foco na atenção, ou seja, quando algo toca, chama a atenção, fazendoo entrar em estado de alerta, entretanto, ainda não define no que o cartógrafo focará sua atenção. O movimento que se refere a um ponto definido da atenção - foco - é chamado de pouso, que indica que o elemento selecionado, seja visto mais de perto para uma análise. Isto é, "o gesto do pouso indica que a percepção, seja, ela visual, auditiva ou outra, realiza uma parada e o campo se fecha, numa espécie de zoom. Um novo território se forma, o campo de observação se reconfigura.” (PASSOS; KASTRUP; ESCÓSSIA, 2009, p. 43). O pouso é dividido em tipos de atenção: a joia, a página do livro, a sala, o pátio e a paisagem, elementos trazidos por Kastrup dos estudos de Vermersch (2002) sobre as janelas atencionais. A janela-joia, caracterizada como micro, tem a atenção extremamente focada e minuciosa, refere-se a uma cegueira atencional (MACK \& ROCK, 1998), que impede a visão do que está fora do foco. A janelapágina, possibilita uma inserção para fora do foco de atenção, ampliando a visão do campo perceptivo. A janela-sala permite a divisão da atenção com mais de um campo. A janela-pátio é caracterizada por atividades de deslocamento e orientação (KASTRUP, 2007). A janelapaisagem permite ao observador ter uma imagem ampla do que está sendo pesquisado, possibilita a conexão entre dois itens distantes na realização de movimentos rápidos. Sendo assim, cada uma das janelas caracteriza um tipo de pouso. Janela-micro é a única que define um foco de investigação, as demais possibilitam ao cartógrafo analisar um campo mais amplo, dependendo de como ocorre o processo de pouso da atenção. O quarto e último movimento é o 
reconhecimento atento de $\mathrm{H}$. Bergson, que caracteriza-se por uma atitude investigativa sobre o pouso, ou seja, sobre o que chamou a atenção do cartógrafo. É a reconfiguração do território da observação. Representa a análise propriamente dita.

Esse método está presente nas pesquisas desenvolvidas no GPe-dU UNISINOS/CNPq, não só como método de pesquisa, mas também como método provocador do desenvolvimento de novas metodologias e práticas que estejam alinhadas a necessidade de compreender o fenômeno das aprendizagens na sua complexidade - social, política, cognitiva, afetiva e tecnológica (SCHLEMMER; LOPES, 2012). De acordo com os autores, apesar de o método estar orientado para a prática da pesquisa em ciências humanas, tem-se investigado a potência desse método para acompanhar processos de aprendizagem em contextos de hibridismo, multimodalidade, pervasividade e ubiquidade, bem como a possibilidade de apropriação do método por professores e estudantes em seus próprios percursos de aprendizagem. Dessa forma, o interesse dos autores tem sido explorar alguns elementos relacionados à cultura híbrida, multimodal, pervasiva e ubíqua e aos novos regimes de ação, participação e socialização da experiência. Assim, desde 2010, o método cartográfico de pesquisa-intervenção vem sendo adaptado, enquanto prática pedagógica, por Schlemmer \& Lopes (2012, 2016); Schlemmer (2014); Schlemmer, Chagas, Schuster (2015).

A inspiração no método cartográfico de pesquisa-intervenção para desenvolver uma prática pedagógica intervencionista foca, principalmente, nos movimentos da atenção proposto por Kastrup e outros. Salientamos que a proposta não é a de transpor o método, mas experimentar os movimentos da cartografia na construção de metodologias e práticas pedagógicas agregativas e engajadoras.

Nesse caso, faz uso da metáfora das pistas como inspiração para conceber narrativas, as quais vinculadas com o rastreio, toque, pouso e reconhecimento atento, se fazem presente na concepção e desenvolvimento de missões, sendo possível ainda, servir como elemento na própria progressão no jogo "achievements".

\section{A Gamificação}

Segundo Schlemmer (2014), a gamificação consiste em utilizar a forma de pensar dos game, os estilos e as estratégias de games, bem como os elementos presentes no design de games, tais como: mecânicas, dinâmicas (M\&D), em contextos não game, como forma engajar os sujeitos na resolução de problemas (ZIECHERMANN; LINDER, 2010; ZICHERMANN; 
CUNNINGHAM, 2011; DETERDING et al. 2011; KAPP, 2012), em diferentes áreas, níveis e contextos educacionais.

A Gamificação se ocupa então, de analisar os elementos que estão no design de jogo e o tornam divertido, adaptando-os para contextos que normalmente não são considerados jogos, criando assim, uma camada de jogo num contexto, aplicação ou produto, no lugar de ser, na origem, um jogo. O conceito se popularizou a partir de 2010, pela sua ampla utilização em diversos contextos, tais como: marketing, educação, estratégia militar, negócios, dentre outros.

De acordo com Schlemmer (2014, p. 77) a gamificação pode ser pensada a partir de pelo menos duas perspectivas:

PERSUASÃO, que estimula a competição, tendo um sistema de pontuação, de recompensa e de premiação, etc., o que do ponto de vista da educação, reforça uma perspectiva epistemológica empirista, como o que encontramos no PBL - points, badges e leaderboard.

Segundo Schlemmer $(2014,2015)$, a perspectiva da gamificação enquanto persuasão é mais fácil de ser encontrada, pois, se origina na teoria comportamentalista e tem como objetivo motivar comportamento e direcionar os sujeitos para determinadas ações. É simples, fácil de ser realizada, é escalável e envolve baixo custo, por isso se disseminou rapidamente. Muitos autores, tais como Chou (2015) refere que os pontos, as medalhas e o quadro de ranking são importantes como bônus, dependendo do contexto. Segundo ele, existe uma diferença entre motivação extrínseca (onde você está envolvido por causa de um objetivo ou recompensa) e a motivação intrínseca (onde a atividade em si é divertida e emocionante, com ou sem uma recompensa). A perspectiva do PBL é denominada por Chou (2015) como a "casca de uma experiência de jogo", é uma visão reducionista da gamificação e, muitas vezes, presta um desserviço à área, uma vez que pessoas com conhecimento superficial sobre a metodologia e a filosofia da gamificação acabam por acreditar que gamificar algo consiste basicamente na criação de um sistema de pontuação, distribuição de medalhar e quadro de ranking, reduzindo a gamificação a um modismo, algo superficial e de baixo poder de inovação.

COLABORAÇÃO E COOPERAÇÃO, instigada por missões, desafios, descobertas, empoderamento em grupo, o que do ponto de vista da educação leva a perspectiva epistemológica interacionista-construtivista-sistêmica (inspirados, por exemplo, por elementos presentes nos Massively Multiplayer Online Role Play Games - MMORPG) (SCHLEMMER, 2015; MACHADO et al., 2015). 
Quadro 01: Perspectivas da gamificação

\begin{tabular}{|c|c|c|c|}
\hline GAMIFICAÇÃO & M\&D & $\begin{array}{c}\text { Mecanismos Sócio } \\
\text { Cognitivos }\end{array}$ & $\begin{array}{c}\text { Concepção } \\
\text { Epistemológica }\end{array}$ \\
\hline Persuasão & $\begin{array}{l}\text { PBL - points, badges e } \\
\text { leaderboard }\end{array}$ & competição & Empirista \\
\hline $\begin{array}{l}\text { Construção Coletiva do } \\
\text { conhecimento }\end{array}$ & $\begin{array}{l}\text { Narrativas, Missões, } \\
\text { Desafios, Enigmas, } \\
\text { Itens Colecionáveis, } \\
\text { Pista Vivas }{ }^{3}, \text { Pistas } \\
\text { Online }^{4}, \text { Pistas }^{5} \\
\text { Geográficas }^{5}, \\
\text { Bibliotecas Viva ou } \\
\text { Biblioteca Humana }^{6}, \\
\text { Achievements }^{7} \text { e EXP }\end{array}$ & $\begin{array}{l}\text { colaboração e } \\
\text { cooperação }\end{array}$ & $\begin{array}{l}\text { Interacionista } \\
\text { Conectiva, reticular }\end{array}$ \\
\hline
\end{tabular}

Fonte: Schlemmer, 2015; Machado et al., 2015.

Desse modo, segundo Schlemmer (2015), na origem da gamificação de um processo, estão a compreensão do problema e o contexto, o que envolve compreender a cultura dos sujeitos, do ambiente e os objetivos. A partir dessas compreensões, é possível pensar no conjunto de $M \& D$, que será utilizada para desenvolver a gamificação, o que permitirá identificar em que perspectiva ela se situa, podendo, em um mesmo processo gamificado, ter a combinação de ambas. A seguir é apresentado o Cosmograma de Gamificação.

\footnotetext{
3 especialistas, pessoas vinculadas ao local ou a problemática abordada na gamificação - referência sobre o conhecimento necessário para desenvolver uma determinada missão.

${ }^{4}$ elementos digitais que fornecem algum elemento que pode auxiliar no desenvolvimento da missão. Pode-se utilizar QRCodes, RM e RA.

${ }^{5}$ local onde há um objeto ou uma informação relevante para o desenvolvimento de uma determinada missão.

${ }^{6}$ o conceito de Biblioteca Humana ou Biblioteca Viva surge a partir de um movimento que começou na Dinamarca em 2000 , com a ONG Stop the Violence, formada por Ronni Abergel, Erich Kristoffersen, Asma Mouna, Thomas Bertelsen e Dany Abergel. Esse movimento surge com o objetivo de quebrar estereótipos e desenvolver ações valorizativas entre pessoas com traços étnicos, culturais e de gênero diferentes, visando o entendimento entre os diversos membros de uma comunidade. Essa ideia foi exportada e está presente em mais de sessenta países. Em uma biblioteca humana as pessoas se transformam em "livros" a partir do seu desejo de socializar as suas experiências de vida possibilitando um diálogo entre sujeitos que normalmente não têm a oportunidade de falar um com o outro. A Biblioteca Humana aproxima as pessoas, para incentivar a aprendizagem intercultural e o desenvolvimento pessoal. O contato com esses "livros humanos", com diferentes pontos de vista, valores e percursos de vida, favorece o desenvolvimento de novas formas de construção do conhecimento.

${ }^{7}$ Conquistas - são objetivos que o jogador pode alcançar durante o jogo ou processo gamificado. Eles podem ser explícitos ou secretos, ou seja, que o sujeito descobre durante o processo de jogar

${ }^{8}$ Nível de EXP ou XP (experiência) - o que permite progredir na gamificação, ocorreu na medida em que os jogadores desbloqueiam os achievements de cada missão (aprendizagem).
} 
Quadro 01: Cosmograma da Gamificação

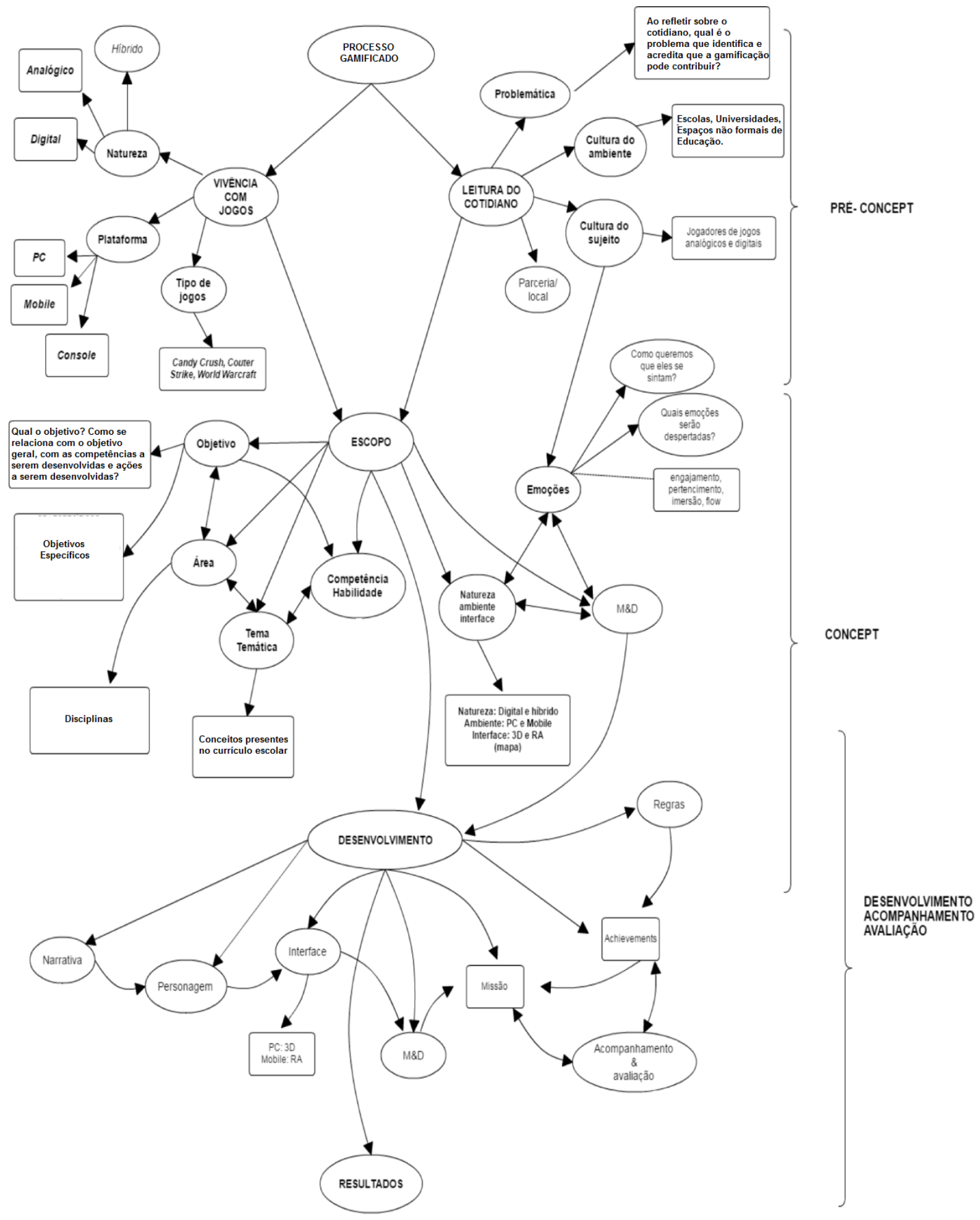




\section{A Cultura híbrida e multimodal}

$\mathrm{O}$ viver e conviver de determinado grupo social evidencia um agir próprio, cria rituais que representam as emoções, estabelece valores comuns, normas para a própria convivencia, construindo uma cultura, o que permite, por exemplo, referir uma cultura digital, uma cultura gamer, uma cultura maker e, mais recentemente, uma cultura híbrida e multimodal.

Maturana e Yáñez (2009, p. 216) afirmam que "A cultura não predetermina o viver que se viverá, mas quem cresce nela a incorpora, e sua corporalidade [corporificação] se transforma de modo que, a menos que ante uma disjuntiva ele ou ela reflexione sobre o que faz, escolhe sem escolher viver, o que o viver a cultura implica". Assim, a manutenção da cultura existente, a transformação, o desenvolvimento e/ou a recriação está relacionada ao grau de consciência dos seres humanos em relação a si e ao outro, no sistema social ao qual pertencem.

Nesse contexto, Schlemmer, Backes e La Rocca (2016), referem a sociedade intercultural e multicultural que se desenvolve e, ao mesmo tempo, impulsiona o desenvolvimento de diferentes tecnologias analógicas e digitais, de forma que, simultaneamente, podemos estar interagindo num espaço analógico, presencial físico e num espaço digital virtual, online; com objetos tanto analógicos, quanto digitais e desses combinados, enfim, num contexto híbrido e multimodal.

O híbrido é compreendido a partir de Latour (1994, 2012), enquanto constituído por múltiplas matrizes, misturas de natureza e cultura, portanto a não separação entre cultura/natureza, humano/não humano, etc. No contexto dessa pesquisa, o híbrido é compreendido quanto à natureza dos espaços (geográfico e digital), quanto à presença (física e digital), quanto às tecnologias (analógicas e digitais) e quanto à cultura (pré-digital e digital).

De acordo com Schlemmer (2014, 2015, 2016), por multimodal, entendem-se as distintas modalidades educacionais imbricadas, ou seja, a modalidade presencial-física e modalidade online e, sendo online, podendo combinar elementos de eletronic learning, mobile learning, pervasive learning, ubíquos learning, immersive learning, gamification learning e Game Based Learning.

É nesses novos espaços que os sujeitos, em movimentos nômades agem e interagem, tecendo relações num imbricamento com outros atores humanos e não humanos, em diferentes tempos, na construção de um mundo de significados. Isso nos leva a pensar que 
uma nova compreensão de cultura e de sociedade possa estar emergindo, numa perspectiva de coexistência, de respeito mútuo, de solidariedade interna, de reconhecimento do outro como legítimo outro na interação.

Interessa-nos compreender o que essas mudanças podem significar para os diferentes sujeitos que compõe o contexto educacional. Como se dá a interação entre os docentes e os estudantes? Como se dá o engajamento nos processos de ensino e de aprendizagem? De que forma essa interação contribui para a própria formação docente. E por fim, o que pode ser feito - nas escolas, nas organizações, incluindo as universidades, para potenciar o desenvolvimento de metodologias inventivas e práticas pedagógicas agregativas e engajadoras?

\section{Metodologia da Pesquisa}

A pesquisa é qualitativa, do tipo exploratória e faz uso do método cartográfico de pesquisa-intervenção, proposto por Kastrup (2007; 2008), Passos, Kastrup e Escóssia (2009) Passos, Kastrup e Tedesco (2014).

Segundo Kastrup (2007), a cartografia é um método que visa acompanhar um processo, e não representar um objeto. Trata-se de investigar um processo de produção, sem buscar estabelecer um caminho linear para atingir um fim. O cartógrafo, pessoa que desenvolve a cartografia, o faz por meio da "atenção cartográfica", que segundo Kastrup (2007, p.15), está baseada no conceito de "atenção flutuante" de Freud e no conceito de "reconhecimento atento" de Bergson. Assim, a autora define a atenção cartográfica como concentrada e aberta, caracterizando-se por quatro variedades (movimentos): o rastreio, o toque, o pouso e o reconhecimento atento.

o rastreio, se caracteriza pela exploração/varredura do campo - no caso dessa pesquisa espaços geográficos e online em busca de pistas - informações - para compreensão dos processos;

o toque, aciona o processo de seleção - consiste nesse caso a partir de Schlemmer (2016 e 2017) na seleção das pistas geográficas, pistas online e pistas vivas, para compor a pesquisa;

o pouso se refere a parada, zoom nas pistas, escolha/definição e;

o reconhecimento atento, a percepção do contexto global.

O objetivo do cartógrafo é justamente cartografar um território que, em princípio, não habitava, compreender os planos de força que nele atuam e, produzir conhecimento ao longo de 
um percurso de pesquisa, o que envolve a atenção e, com ela, a própria criação do território de observação. (KASTRUP, 2007, p. 20).

Por se tratar de pesquisa-intervenção, a análise se dá no processo, ou seja, no movimento da cartografia, o que possibilita realizar a intervenção enquanto o processo está ocorrendo.

Como instrumentos e materiais foram utilizados a observação participante, diário de bordo e registros em forma de texto, áudio, fotografia e vídeo digitais deixados na forma de rastros em diferentes espaços de interação. O campo empírico da pesquisa foi constituído conforme a seguir:

Quadro 1: situações de aprendizagem/contexto, domínio e participantes:

\begin{tabular}{|c|c|c|}
\hline $\begin{array}{c}\text { SITUAÇÃO DE } \\
\text { APRENDIZAGEM/CONTEXTO }\end{array}$ & DOMÍNIO & PARTICIPANTES/ATORES \\
\hline 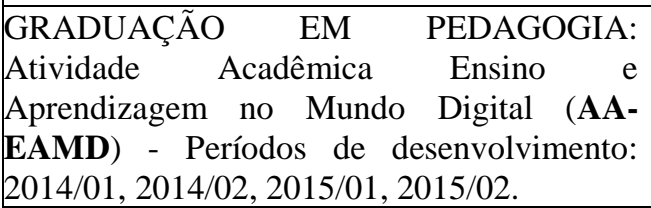 & $\begin{array}{l}\text { Educação } \quad \text { Superior } \\
\text { Licenciatura e Educação } \\
\text { Básica (fundamental) }\end{array}$ & idantes \\
\hline $\begin{array}{lll}\text { GRADUAÇÃO EM JOGOS DIGITAIS: } & \text { JOS } \\
\text { Atividade Acadêmica } & \text { Cognição em Jogos } \\
\text { Digitais - 2014/01 } & & \\
\end{array}$ & $\begin{array}{l}\text { Educação } \quad \text { Superior } \\
\text { Tecnológica }\end{array}$ & $28 \mathrm{e}$ \\
\hline $\begin{array}{l}\text { GRADUAÇÃO EM JOGOS DIGITAIS: } \\
\text { Atividade Acadêmica Contextos em Jogos } \\
\text { Digitais - 2015/01 }\end{array}$ & $\begin{array}{ll}\text { Educação } & \text { Superior } \\
\text { Tecnológica } & \end{array}$ & $22 \mathrm{c}$ \\
\hline $\begin{array}{l}\text { PPG em EDUCAÇÃO: } \quad \text { Seminário de } \\
\text { Educação Digital - 2014/02 e } 2015 / 02\end{array}$ & Pós-Graduação Stricto Sensu & $\begin{array}{l}25 \text { mestrandos e doutorandos do } \\
\text { PPG em Educação e PPG em } \\
\text { Administração }\end{array}$ \\
\hline
\end{tabular}

Fonte: elaborada pela autora.

Nessas situações de aprendizagem/contexto/domínio a metodologia inventiva "Projeto de Aprendizagem Gamificado- PAG”, foi desenvolvida, acompanhada e validada, em conjunto com os diferentes participantes/atores (estudantes da graduação, do mestrado, do doutorado, professores e demais integrantes do GPe-dU UNISINOS/CNPq).

Os dados produzidos na cartografia foram organizados, categorizados e interpretados a partir do referencial teórico que fundamentou a pesquisa.

\section{Resultados e Discussões}

O desenho da metodologia inventiva "Projetos de Aprendizagem Gamificados - PAG", teve origem teórico-conceitual na metodologia de Projetos de Aprendizagem, proposta por Fagundes, Maçada e Sato (1999); na metodologia de Projetos de Aprendizagem baseado em Problemas, adaptada por Schlemmer $(2001,2002)$, no método cartográfico de pesquisa-intervenção, adaptado enquanto 
prática pedagógica por Schlemmer \& Lopes (2012, 2016); Schlemmer (2014); Schlemmer, Chagas, Schuster (2015) e, no conceito e elementos de gamificação propostos por Schlemmer (2014, 2015, 2016).

Da metodologia de projetos de aprendizagem buscou-se:

- a importância da formulação de questões pelo próprio sujeito ${ }^{9}$ que constrói o conhecimento, a partir do que já conhece e da curiosidade, inquietações, conflitos, perturbações num determinado contexto, em seu ambiente de vida;

- a formação de grupos tendo como base questões em comum;

- a aprendizagem da colaboração e da cooperação, uma vez que desenvolver projetos é uma atividade que requer aprender a trabalhar om o outro (colaboração) e também realizar operações mentais com o outro (cooperação), que surgem a partir da necessidade de trocas recíprocas em diversos espaços de interação (presenciais físicos e digitais);

- o planejamento, no qual os aprendizes relacionam o que sabem sobre o problema que desejam investigar (certezas provisórias) e o que ainda não sabem e, portanto precisam pesquisar (dúvidas temporárias); descrevem os objetivos, como vão desenvolvê-lo, como vão produzir as informações, que recursos e materiais vão utilizar, bem como a forma como será socializado;

- a apropriação de diferentes tecnologias para o desenvolvimento dos projetos;

- a avaliação como acompanhamento do percurso e desenvolvimento da aprendizagem, usada para verificar como o sujeito está pensando, que recursos já utiliza, que relações consegue estabelecer, que operações realiza ou inventa;

- o pressuposto do trabalho interdisciplinar, uma vez que há necessidade de diferentes áreas do conhecimento para se desenvolver um projeto.

Do método cartográfico de pesquisa-intervenção, buscou-se:

- a perspectiva da pesquisa-intervenção, sendo que durante o desenvolvimento dos PAG, em diferentes momentos, tanto o docente, quanto os próprios sujeitos atuam como mediadores intervencionista;

- a ideia de trabalhar com a aprendizagem enquanto invenção de problemas (atenção "suplementar", à duração - reconhecimento atento de um contexto), para além da aprendizagem como resolução de problemas (atenção a vida pragmática utilitária);

- a organização por gildas ou clãs;

- a proposta de acompanhamento de percurso;

\footnotetext{
${ }^{9}$ Uma vez que a motivação é intrínseca - própria do sujeito que aprende
} 
- a metáfora das pistas;

- os movimentos da atenção do cartógrafo.

Da gamificação, buscou-se:

- inspiração na forma de pensar dos game, nos estilos e nas estratégias de games, bem como nos elementos presentes no design de games, tais como: mecânicas, dinâmicas (M\&D), como forma engajar os sujeitos na resolução de problemas (ZIECHERMANN e LINDER, 2010; ZICHERMANN e CUNNINGHAM, 2011; KAPP, 2012), em diferentes áreas, níveis e contextos educacionais;

- a perspectiva da gamificação enquanto colaboração e cooperação (SCHLEMMER, 2014), instigada por M\&D, tais como: narrativas, missões, desafios, enigmas, itens colecionáveis, pistas $\operatorname{vivas}^{10}$, pistas online ${ }^{11}$, pistas geográficas ${ }^{12}$ (as quais dão origem a Biblioteca Viva ou Biblioteca Humana $\left.{ }^{13}\right)^{14}$, achievements ${ }^{15}$ e $\operatorname{EXP}^{16}$, o que instiga a descobertas, empoderamento em grupo, o que do ponto de vista da educação leva a perspectiva epistemológica interacionista (inspirados, por exemplo, por elementos presentes nos Massively Multiplayer Online Role Play Games - MMORPG) (SCHLEMMER, 2015).

A análise dos dados, no que se refere a Atividade Acadêmica Ensino e Aprendizagem no Mundo Digital (AA-EAMD), da GRADUAÇÃO EM PEDAGOGIA, indica um impacto significativo da metodologia PAG, tanto no que se refere ao processo de aprendizagem das acadêmicas, quanto na prática docente desenvolvidas por elas nas escolas, nas quais desenvolveram seus respectivos PAG Nesse processo de construção do conhecimento, muitas estudantes que já eram docentes experientes, foram desacomodadas e provocadas a repensar as metodologias e práticas que desenvolviam, a partir da

\footnotetext{
10 especialistas, pessoas vinculadas ao local ou a problemática abordada na gamificação - referência sobre o conhecimento necessário para desenvolver uma determinada missão.

${ }^{11}$ elementos digitais que fornecem algum elemento que pode auxiliar no desenvolvimento da missão. Pode-se utilizar QRCodes, RM e RA.

12 local onde há um objeto ou uma informação relevante para o desenvolvimento de uma determinada missão.

13 o conceito de Biblioteca Humana ou Biblioteca Viva surge a partir de um movimento que começou na Dinamarca em 2000 , com a ONG Stop the Violence, formada por Ronni Abergel, Erich Kristoffersen, Asma Mouna, Thomas Bertelsen e Dany Abergel. Esse movimento surge com o objetivo de quebrar estereótipos e desenvolver ações valorizativas entre pessoas com traços étnicos, culturais e de gênero diferentes, visando o entendimento entre os diversos membros de uma comunidade. Essa ideia foi exportada e está presente em mais de sessenta países. Em uma biblioteca humana as pessoas se transformam em "livros" a partir do seu desejo de socializar as suas experiências de vida possibilitando um diálogo entre sujeitos que normalmente não têm a oportunidade de falar um com o outro. A Biblioteca Humana aproxima as pessoas, para incentivar a aprendizagem intercultural e o desenvolvimento pessoal. O contato com esses "livros humanos", com diferentes pontos de vista, valores e percursos de vida, favorece o desenvolvimento de novas formas de construção do conhecimento.

14 essas foram criadas a partir da inter-relação com o método cartográfico de pesquisa-intervenção.

${ }^{15}$ Conquistas - são objetivos que o jogador pode alcançar durante o jogo ou processo gamificado. Eles podem ser explícitos ou secretos, ou seja, que o sujeito descobre durante o processo de jogar

${ }^{16}$ Nível de EXP ou XP (experiência) - o que permite progredir na gamificação, ocorreu na medida em que os jogadores desbloqueiam os achievements de cada missão (aprendizagem).
} 
reflexão sobre o seu próprio processo de aprendizagem que estava ocorrendo, na relação com o que os seus estudantes também vivenciam enquanto estão aprendendo (significação e ressignificação). Essa tomada de consciência é significativa para a transformação das metodologias e práticas pedagógicas, pois o professor começa a estabelecer diferenciações entre: 1) o "uso de" determinadas TD na educação $X$ a significação das TD no seu processo de aprendizagem, o que possibilita a criação de situações de aprendizagem, nas quais os sujeitos operam com essas tecnologias, vivenciando-as na construção de experiências que possibilitam a significação no processo de aprendizagem; 2) a "transmissão de conteúdo" X a construção do conhecimento; 3) o "aplicar" uma metodologia X o desenvolver uma metodologia, 4) o "dar aulas" X a construção de espaços de aprendizagem.

Esses PAG foram construídos na perspectiva do movimento "Games for Change" (desenvolvidos partir de problemáticas educacionais relevantes, identificadas no contexto das escolas de educação básica, onde as estudantes da pedagogia atuavam, provocando impacto nas instituições onde foram desenvolvidas). Ao todo, somente no ano de $2015^{17}$ durante os dois semestres, os PAG desenvolvidos envolveram 11 municípios; 25 profissionais da educação, pais, profissionais da comunidade e mais de 240 alunos da educação infantil ao $6^{\circ}$ ano, incluindo também projeto de ONG. Salienta-se o envolvimento da comunidade, pois, sendo essa uma metodologia que trabalha com o conceito de sala de aula ampliada, dependendo da temática abordada pelos estudantes no desenvolvimento dos PAG, foi necessária a interação com outros espaços (Pistas Geográficas) e profissionais (Pistas Vivas) que integram as cidades.

É fundamental salientar que durante o percurso da pesquisa houve uma evolução no que se refere ao desenho da própria metodologia - Projetos de Aprendizagem Gamificados, que resultou da própria metodologia da pesquisa (método cartográfico de pesquisa-intervenção), o que possibilitou a articulação entre elementos vindos: 1) da cartografia das práticas pedagógicas desenvolvidas, 2) do retorno das avaliações constantes, realizadas pelos sujeitos participantes das diferentes situações de aprendizagem/contextos, 3) das reflexões dos docentes sobre a prática desenvolvida - realizadas ao final de cada encontro com os estudantes, 4) das discussões nos encontros das práticas de pesquisa com os orientandos de mestrado e doutorado e; 5) do aprofundamento teórico e metodológico.

\footnotetext{
${ }^{17}$ Não temos os dados referentes a 2014, mas somente de 2015, em função da evolução da própria pesquisa, no que se referiu a metodologia e a prática pedagógica desenvolvida, o que incluiu outros elementos da gamificação, tais como a narrativa inicial, que instigava as estudantes a realizar a leitura crítica do cotidiano das escolas a fim de identificar problemáticas relevantes, as quais os games ou processos gamificados poderiam contribuir quanto ao processo de aprendizagem dos estudantes; a formação de Clãs e as missões, objetivos e achievements.
} 
Como resultado principal, construído no percurso da pesquisa, a metodologia inventiva Projetos de Aprendizagem Gamificados - PAG foi sistematizada, dando origem a imagem a seguir, que serve de elemento orientador para o seu desenvolvimento.

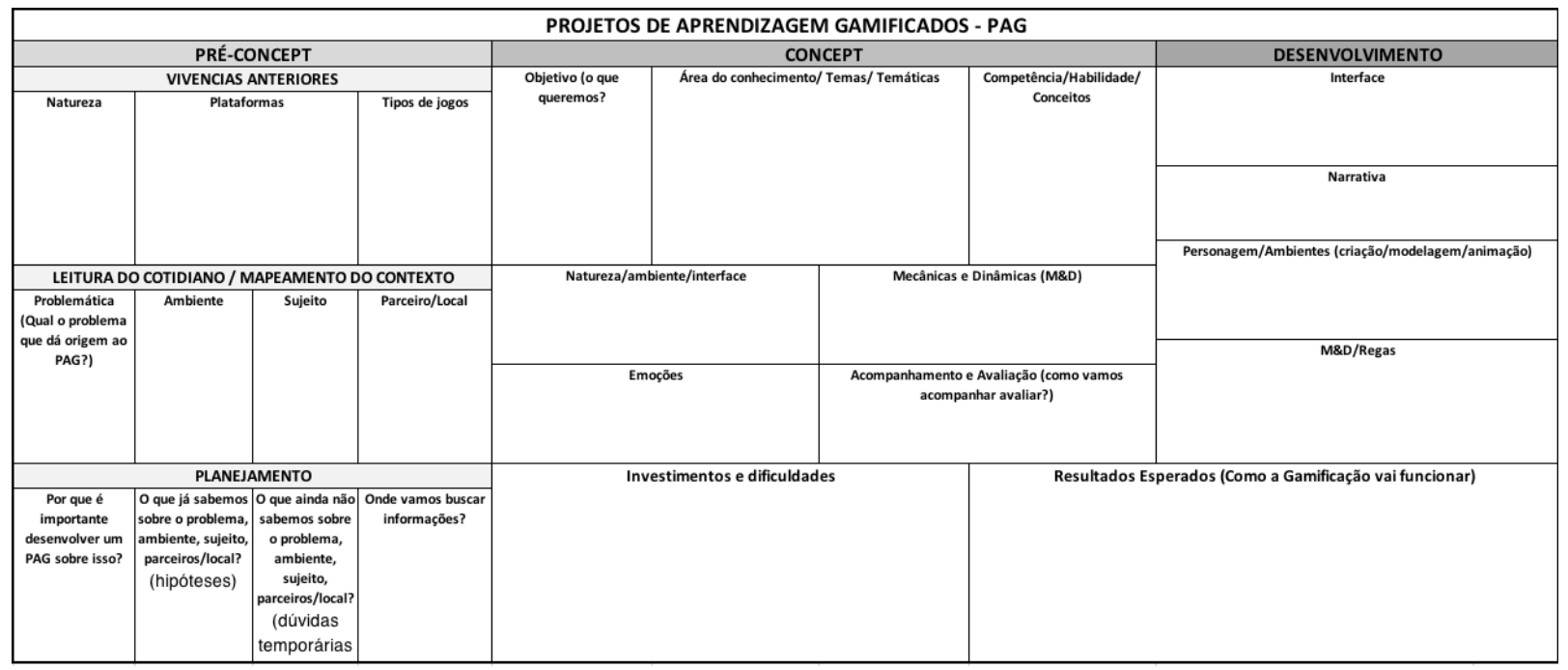

A metodologia PAG tem sido desenvolvida com doutorandos, mestrandos, graduandos, professores e estudantes da Educação Básica, em municípios do estado do Rio Grande do Sul, na perspectiva da ampliação dos espaços de aprendizagem para a Cidade constituindo, dessa forma, espaços de convivência (MATURANA 2002) híbridos, multimodais, pervasivos e ubíquos (SCHLEMMER $2015,2016)$, a partir de uma proposta que inclui o desenvolvimento de games \& processos gamificados, considerando a abordagem proposta pelo movimento "Games for Change".

\section{Considerações Finais}

Retomando o problema de pesquisa que deu origem a esse artigo, é possível concluir que:

- a gamificação, enquanto Construção Coletiva do conhecimento (quadro 01), o que implica em mecânicas e dinâmicas, tais como: narrativas, missões, desafios, enigmas, itens colecionáveis, pista vivas, pistas online, pistas geográficas, bibliotecas viva ou biblioteca humana, achievements e EXP;

aliada a:

- elementos presentes no método cartográfico de pesquisa-intervenção, especialmente no que se refere ao acompanhamento dos percursos e realização de intervenção ainda durante o processo, bem como a metáfora das pistas e os movimentos da atenção do cartógrafo (rastreio, toque, pouso e reconhecimento atento), serviram de inspiração 
para conceber a composição, inicialmente das trilhas e, posteriormente das narrativas e das missões, bem como para a própria progressão na gamificação, quanto aos objetivos, achievements e exp;

e, vinculada aos:

- elementos presentes nos projetos de aprendizagem: Problemática (Qual o problema que dá origem ao projeto); Por que é importante desenvolver um projeto sobre isso? $\mathrm{O}$ que já sabemos sobre o problema, ambiente, sujeito, parceiros/local? (hipóteses) O que ainda não sabemos sobre o problema, ambiente, sujeito, parceiros/local? (dúvidas temporárias) Onde vamos buscar informações?

possibilitaram, suportados por uma Epistemologia Reticular, Conectiva e Atópica (DI FELICE, 2009, 2012) e fundamentados na cognição inventiva, proposta por Kastrup, Tedesco e Passos (2015), o desenvolvimento de uma metodologia inventiva - Projetos de Aprendizagem Gamificados - a qual se mostrou mais significativa aos atuais sujeitos da aprendizagem, que integram a cultura híbrida e multimodal.

A metodologia de Projetos de Aprendizagem Gamificados, ao valorizar múltiplos espaços sociais como espaços de construção de conhecimento, instigando a cooperação entre escola, comunidade e segmentos sociais, tem potencial para se constituir numa das possibilidades para a reconfiguração do contexto educacional vigente que tem recebido crítica por estar perdendo significado para os sujeitos da aprendizagem e sociedade, frente às transformações sócio culturais contemporâneas. Dessa forma, é possível dizer que o objetivo proposto na pesquisa foi atingido. 


\section{Referências}

CASTELLS, M. A Sociedade em Rede. São Paulo: Paz e Terra, 1999.

CHOU, Yu-kai. Octalysis: Complete Gamification Framework. 2015. Disponível em: <www.yukaichou.com>. Acesso em: 1 abr. 2015.

DELEUZE, G.; GUATTARI, F. Mil platôs - capitalismo e esquizofrenia, vol. 1 / Tradução de Aurélio Guerra Neto e Célia Pinto Costa. 1 ed. Rio de janeiro: Ed. 34, 1995. 94 p. (Coleção TRANS).

DETERDING, S. at al. (2011) Gamification: Toward a Definition. Conference on Human Factors in Computing Systems, pp. 7-12, Vancouver, British Columbia, Canada: ACM. Disponível em: < http://gamification-research.org/wpcontent/uploads/2011/04/02Deterding-Khaled-Nacke-Dixon.pdf>. Acesso em: 25 abr. 2015.

DI FELICE, M. Paisagens pós-urbanas: o fim da experiência urbana e as formas comunicativas do habitar. São Paulo: Annablume, 2009. Coleção Atopos.

DI FELICE, M. Redes Sociais Digitais, epistemologias reticulares e a crise do antropomorfismo social. Revista USP, v. 22, p. 06-19, 2012.

FAGUNDES, L. C.; SATO, L. S.;. MAÇADA, D. L. Projeto? O que é? Como se faz? In: Aprendizes do Futuro: as inovações começaram! Coleção Informática para a mudança na Educação. Brasília, MEC, 1999.

KAPP, K. The Gamification of Learning and Instruction: Game-based Methods and Strategies for Training and Education. Pfeiffer, 2012.

KASTRUP, V. O funcionamento da atenção no trabalho do cartógrafo. Psicol. Soc. [online]. 2007, vol.19, n.1, p. 15-22. Disponível em: <http://www.scielo.br/scielo.php?script=sci_pdf\&pid=S0102$71822007000100003 \& \operatorname{lng}=$ pt\&nrm=iso\&tlng=pt $>$. Acessado em: 1 jun. 15 .

KASTRUP, V. O método cartográfico e os quatro níveis da pesquisa-intervenção. Em: CASTRO, L.R.; BESSET, V. (orgs). Pesquisa-intervenção na infância e adolescência. Rio de Janeiro: Nau editora, 2008.

PASSOS, E.; KASTRUP, V. e ESCÓSSIA, L. (orgs). Pistas do método da cartografia: Pesquisaintervenção e produção de subjetividade. Porto Alegre : Sulina, 2009.

PASSOS, E.; KASTRUP, V.; TEDESCO, S. Pistas do método da cartografia: a experiência da pesquisa e o plano comum. Porto Alegre: Sulina, 2014.

KASTRUP, V. TEDESCO, S. PASSOS, E. Políticas da Cognição: Porto Alegre: Sulina, 2015. LATOUR, B. Jamais fomos modernos. Rio de Janeiro: Editora 34, 1994. 
LATOUR, B. Reagregando o social: uma introdução à teoria do ator-rede. São Paulo: EDUSC, 2012.

LÉVY, P. Cibercultura. Rio de Janeiro: Editora 34, 1999.

MACK, A., \& ROCK, I. Inattentional blindness. Cambridge, MA: MIT Press. 1998.

MACHADO, L.; SCHLEMMER, E.; CASTRO, A. R. de; MONTICELLI, J. M.; CRUZ, R. R.; WALLAUER, M. ; BARTH, M. A Gamificação como Estratégia de Capacitação e o Estado de Flow: um Estudo de Caso em uma Empresa da Área de Tecnologia da Informação (TI) da Região Sul do Brasil. Teresina PI: SBGames, 2015. v. 1. p. 1015-1024.

MATURANA, R. Humberto; YÁÑEZ, Ximema Davila. Habitar humano em seis ensaios de biologia-cultural. São Paulo: Palas Athena, 2009.

MATURANA, H. . A árvore do conhecimento: as bases biológicas da compreensão humana. São Paulo: Palas Athena, 2002.

PAPERT, S. The Connected Family: Bridging the Digital Generation Gap. Atlanta, Georgia: Longstreet Press, 1996.

PIAGET, J. A Tomada de Consciência. São Paulo: Melhoramentos, 1978.

SCHLEMMER, E. Projetos de Aprendizagem Baseados em Problemas: uma metodologia interacionista/construtivista para formação de comunidades em Ambientes Virtuais de Aprendizagem.. In: Congresso Internacional de Informática Educativa 2001 Universidad Nacional de Educación a Distância UNED 2001, 2001, Madrid. Anais disponível em CDROM., 2001.

SCHLEMMER, E. AVA: Um ambiente de convivência interacionista sistêmico para comunidades virtuais na cultura da aprendizagem. Porto Alegre: URFGS, 2002. Tese Doutorado.

TREIN, D.; SCHLEMMER, E. Projetos de Aprendizagem Baseados em Problema no Contexto da Web 2.0: Possibilidades para a Prática Pedagógica. Revista e-Curriculum (PUCSP), v. 4, p. 1-20, 2009.

SCHLEMMER, E.; LOPES, D. de Q.. A Tecnologia-conceito ECODI: uma perspectiva de inovação para as práticas pedagógicas e a formação universitária. In VII Congresso Iberoamericano de Docência Universitária, 2012, Porto, Portugal. Faculdade de Psicologia e de Ciências da Educação da Universidade do Porto.

SCHLEMMER, E. Gamificação em espaços de convivência híbridos e multimodais: design e cognição em discussão. Revista da FAEEBA-Educação e Contemporaneidade, v. 23, n. 42, 2014.

SCHLEMMER, E. Anatomia no metaverso Second Life: uma proposta em i-Learning. São Leopoldo 2013 (Relatório de Pesquisa). 
SCHLEMMER, E. Gamificação em Espaços de Convivência Híbridos e Multimodais: uma experiência no ensino superior. 2016. (Relatório de pesquisa).

SCHLEMMER, E. Gamificação em espaços de convivência híbridos e multimodais: a educação na cultura digital. 2017. (Relatório de pesquisa).

SCHLEMMER, E.; LOPES, D. Q. . AVALIAÇÃO DA APRENDIZAGEM EM PROCESSOS GAMIFICADOS: DESAFIOS PARA APROPRIAÇÃO DO MÉTODO CARTOGRÁFICO. In: ALVES, Lynn; COUTINHO, Isa de Jesus. (Org.). JOGOS DIGITAIS E APRENDIZAGEM. 1ed.Campinas: Papirus Editora, 2016, v. 1, p. 179-208.

SCHLEMMER, E.; CHAGAS, W. S.; SCHUSTER, B. E. Games e Gamificação na modalidade EAD: da prática pedagógica na formação Inicial em Pedagogia à prática pedagógica no Ensino Fundamental. In: IV Seminário Web Currículo e XII Encontro de Pesquisadores. São Paulo: PUC-SP, 2015.

SHLEMMER, E. Gamificação em contexto de hibridismo e multimodalidade na educação corporativa. Revista FGV Online, v. 5, p. 26-49, 2015.

SCHLEMMER, E. Hibridismo, Multimodalidade e Nomadismo: codeterminação e coexistência para uma Educação em contexto de ubiquidade. In: Daniel Mill;Aline Reali. (Org.). Educação a distância, qualidade e convergências: sujeitos, conhecimentos, práticas e tecnologias. 1ed.São Carlos: EdUFSCar, 2016, v. 1, p. 1-24.

SCHLEMMER, E. Games e Gamificação: uma alternativa aos modelos de EaD. Revista Iberoamericana de Educación a Distancia, v. 19, p. 1-12, 2016.

SCHLEMMER, E.; BACKES, L.; LA ROCCA, F. L'Espace de coexistence hybride, multimodal, pervasif et ubiquitaire: le quotidien de 1?éducation à la citoyenneté. Educacao Unisinos (Online), v. 20, p. 297-306, 2016.

ZICHERMANN, G.; LINDER, J. "Game-Based Marketing." Jargonlab, Inc. and Joselin Linder. 2010.http://www.slate.com/id/2289302/

ZICHERMANN, G. ; CUNNINGHAM, C. Gamificationby Design: Implementing Game Mechanics in Web and Mobile Apps. O'Reilly, Sebastopol, 2011. 
Momento: diálogos em educação, E-ISSN 2316-3100, v. 27, n. 1, p. 42-69, jan./abril. 2018 
Momento: diálogos em educação, E-ISSN 2316-3100, v. 27, n. 1, p. 42-69, jan./abril. 2018 